\title{
DUGAAN CADANGAN BIOMASA TUMBUHAN BAWAH DAN SERASAH PADA BEBERAPA PETAK TEGAKAN DI KAWASAN HUTANPENDIDIKAN ANGGORI
}

\section{(Biomass Reserve Estimation of Understorey and Plant Litter on Several Stand Plots in Anggori Educational Forest)}

\author{
IRMA FINCE PARIRI ${ }^{1}$, WOLFRAM Y. MOFU ${ }^{1 凶}$, ANA TAMPANG $^{1}$ \\ Jurusan Kehutanan, Fakultas Kehutanan Universitas Papua Manokwari, Papua Barat, 98314. \\ Tlp/Fax: +62986211065. \\ $\triangle$ Penulis Korespondensi: Email: wmofu@gmail.com \\ Diterima: 27 Sept 2020| Disetujui:30 Okt 2020
}

\begin{abstract}
Abstrak. Tujuan dari penelitian ini adalah untuk dapat memberi informasi tentang cadangan biomassa tumbuhan bawah dan serasah pada beberapa petak tegakan di Hutan Pendidikan Anggori. Hasil penelitian menunjukan bahwa petak Manilkara fasciculate memiliki jumlah jenis tumbuhan bawah sebanyak rata-rata 4-11 jenis tumbuhan dengan jumlah individu 11-26 individu per plot pengamatan. Biomassa tumbuhan bawah tertinggi diperoleh pada petak tegakan Manilkara fasciculate yaitu sebesar $161,333 \mathrm{gr} / \mathrm{m}^{2}$ sedangkan karbon stocknya 0,807 ton $\mathrm{C} / \mathrm{Ha}$. Biomassa serasah paling banyak terdapat pada petak Pometia coreacea yaitu 324,667 gram $/ \mathrm{m}^{2}$ dan karbon stocknya 1,62 ton C/Ha.
\end{abstract}

Kata kunci: cadangan biomasa, stok karbon, tegakan hutan, tumbuhan bawah, serasah

\begin{abstract}
The objective of this study was to provide information on biomass reserves of the understorey and litter from several stands in the area of Anggori Educational forest. The results showed that the plot for Manilkara fasciculate had 4-11 of understorey plant species with a number of species between 11-26 individuals per plot. The highest biomass was found at the plot of Manilkara fasciculate about $161.333 \mathrm{gr} / \mathrm{m}^{2}$, while the carbon stock was approximately 0.807 tons $\mathrm{C} / \mathrm{Ha}$. In addition, the highest biomass from litter was mostly found in Pometia coreacea stand which was around $324.67 \mathrm{gr} / \mathrm{m}^{2}$ and the carbon stock of 1,62 tons C/Ha.
\end{abstract}

Keywords: Biomass reserve, carbon stock, forest stands, understorey, plant litter

\section{PENDAHULUAN}

Hutan mempunyai peranan yang cukup penting dalam memenuhi kebutuhan hidup manusia. Masyarakat yang tingal di dalam maupun di sekitar hutan memanfaatkan hutan sebagai sumber penghasilan bahan makanan dan minuman, sumber obat-obatan, bahan senjata/perkakas, bahan bangunan/kontruksi, sumber energi, sumber bahan magris/ritual dan lain sebagainya. Pembangunan di bidang kehutanan diarahkan pada pemanfaatan sumberdaya hutan secara optimal dan lestari serta diupayakan untuk meningkatkan kesejahtraan hidup masyarakat (Mamusung, 2005).

Indonesia memiliki hutan tropis terluas di dunia dan memiliki peringkat pertama di Asia Pasifik, dengan jumlah luas hutan mencapai 133,6 juta hektar (Andini, 2017). Dari kekayaan hutan tersebut, Indonesia dipandang dunia 
sebagai salah satu negara yang cukup signifikan dalam mempengaruhi perubahan iklim dunia. Data dari Kementrian LHK menyebutkan bahwa untuk privinsi Papua Barat berdasarkan SK 783/Menhut-II/2014 bahwa luas HL

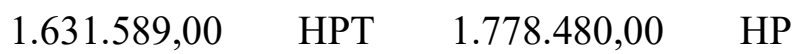
2.188.160,00 HPK 1.474.650,00 (Kementrian LHK, 2016).

Pencegahan deforestasi atau 'Avoided deforestation' (AD)-mengacu pada pencegahan atau pengurangan hilangnya hutan dengan maksud untuk menurunkan emisi gas yang mengakibatkan pemanasan global (Griffiths, 2007). Gas rumah kaca mencakup gas-gas seperti: $\mathrm{CO}_{2}, \mathrm{CH}_{4}, \mathrm{~N}_{2} \mathrm{O}, \mathrm{HFC}_{\mathrm{s}}, \mathrm{PFC}_{\mathrm{s}}, \mathrm{SF}_{6}, \mathrm{NF}_{3}$, $\mathrm{SF}_{5} \mathrm{CF}_{3}, \mathrm{C}_{4} \mathrm{~F}_{9} \mathrm{OC}_{2} \mathrm{H}_{5}, \mathrm{CHF}_{2} \mathrm{OCF}_{2} \mathrm{OC}_{2} \mathrm{~F}_{4} \mathrm{OCHF}_{2}$, $\mathrm{CHF}_{2} \mathrm{OCF}_{2} \mathrm{OCHF}_{2}$. (Suryani, 2013). Namun demikian indonesia berkomitmen untuk untuk mengurangi emisi GRK hingga 26\% di bawah tingkat BAU (business as usual) pada tahun 2020. Beberapa kegiatan yang diupayakan adalah mengurangi deforestasi dan degradasi hutan, konservasi, pengelolaan hutan berkelanjutan dan peningkatan stok karbon hutan (Krisnawati et al. 2015).

Tujuan dari penelitian ini adalah untuk menduga cadangan biomassa yang tersimpan pada tumbuhan bawah dan serasah yang terdapat pada empat petak tegakkan intsia bijuga, pometia coreacea, manilkara fasciculate, dan tectona grandis di kawasan hutan pendidikan anggori. Sementara manfaat dari hasil penelitian ini adalah dapat memberi informasi tentang cadangan biomassa tumbuhan bawah dan serasah pada beberapa petak tegakan guna sebagai data untuk pengelolaan Hutan Pendidikan Anggori selanjutnya.

\section{METODE PENELITIAN}

Penelitian ini dilaksanakan di hutan pendidikan Anggori dan Laboratorium Teknologi Hasil Hutan penelitian berlangsung selama \pm 2 bulan yaitu tanggal 18 Mei 2018 sampai dengan 2 Juli 2018. Peralatan dan bahan yang digunakan dalam penelitian ini antara lain GPS, timbangan, parang, gunting tanaman, pipa ukur $1 \mathrm{~m} \times 1 \mathrm{~m}$, oven, alat tulis menulis. Bahan yang digunakan dalam penelitian adalah kantong plastik, dan tallysheet.

\section{Obyek Penelitian}

Obyek dalam penelitian ini adalah tumbuhan bawah dan serasah yang berada di dalam plot pengamatan pada petak Manilkara fasciculate, Pometia coreacea, Intsia bijuga, dan Tectona grandis di hutan Pendidikan Anggori.

\section{Prosedur Penelitian}

1. Pembuatan Plot Pengamatan dilakukan dengan membuat plot berukuran $1 \mathrm{~m} \times 1 \mathrm{~m}$ sebanyak 3 (tiga) plot di setiap petak tegakan yang menjadi objek pengamatan yaitu Manilkara fasciculate, Pometia coreacea, Intsia bijuga, dan Tectona grandis sehingga total keseluruhan 12 (dua belas) plot pengamatan. Setiap plot pengamatan dilakukan pengambilan titik koordinatnya.

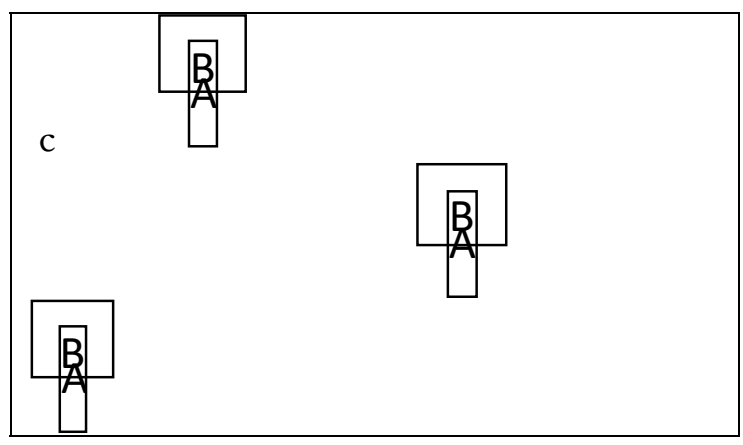

Keterangan:

A : Plot pengamatan tumbuhan bawah dan $\operatorname{serasah}(1 \mathrm{~m} \times 1 \mathrm{~m})$

$\mathrm{B}$ : Plot pengamatan vegetasi tingkat pohon $(10 \mathrm{~m} \times 10 \mathrm{~m})$

$\mathrm{C}:$ Petak tegakkan

2. Pengamatan tumbuhan bawah meliputi pendataan jenis dan jumlah individu pada plot pengamatan. Data pengamatan ditulis dalam tallysheet. Pendataan dilakukan 
sebelum mengambil sampel tumbuhan dan serasah.

3. Pengambilan sampel dilakukan terhadap seluruh tumbuhan bawah dan serasah pada plot pengamatan dan dilakukan dengan cara destruktif. Sampel kemudian dipisahkan antara sampel tumbuhan bawah dan sampel serasah. Setelah itu sampel ditimbang untuk mendapatkan data berat basahnya.

4. Pengamatan dan pendataan vegetasi tingkat pohon disekitar plot pengamatan dengan jarak 10 meter.

5. Pengeringan sampel, setelah sampel diambil dan ditimbang kemudian dimasukan dalam oven pada suhu $80^{\circ} \mathrm{C}$ selama 2-3 hari setelah itu kemudian dihitung berat kering setelah dioven.

\section{Variabel Pengamatan}

Data yang dikumpulkan meliputi data :

1) Jumlah jenis dan individu tumbuhan bawah per plot pengamatan

2) Total Berat Kering tumbuhan bawah dan serasah

3) Vegetasi tingkat pohon sekitar plot pengamatan

Kandungan karbon (carbon stock) dihitung dengan menggunakan pendekatan biomassa dengan asumsi $50 \%$ dari biomassa adalah karbon yang tersimpan (Brown 1997 dalam Windusari dkk. 2012).

\section{Analisis Data}

Data hasil penelitian kemudian dianalisis menggunakan analisis deskriptif dan data disajikan dalam bentuk tabel.

\section{HASIL DAN PEMBAHASAN}

\section{Jumlah Jenis dan Individu Tumbuhan Bawah}

Arboretum Hutan Pendidikan Anggori merupakan areal yang ditanami beberapa jenis endemik Papua namun juga terdapat jenis introduksi. Jenis-jenis pohon tersebut ditanam berdasarkan jenis dalam suatu petak-petak tanaman. Walaupun pada setiap petak ditanami oleh satu jenis pohon namun dalam selang waktu penanaman hingga pada pengamatan diduga telah terjadi interaksi antara vegetasi sekitar ataupun karena aktivitas manusia di area tersebut yang turut mempengaruhi komposi jenis tumbuhan bawah pada petak-petak tegakan di Arboretum Hutan Pendidikan Anggori. Jumlah jenis dan individu tumbuhan bawah pada plot di setiap petak pengamatan dapat dilihat pada lampiran 1 .

Terlihat bahwa jumlah jenis tumbuhan bawah terbanyak dijumpai pada plot pengamatan di tegakan Manilkara fasiculate yaitu rata-rata 4-11 jenis tumbuhan dengan jumlah individu 11-26 individu per plot pengamatan. Pada ketiga petak pengamatan lainnya rata-rata terdiri dari 5 jenis tumbuhan untuk setiap plot pengamatan. Hal ini dikarenakan faktor lingkungan yang berbeda. Menurut Kartasapoetra (1992), faktor-faktor lingkungan yang sangat berpengaruh terhadap vegetasi diantaranya adalah ketinggian tempat, kelembaban udara, suhu udara serta intensitas cahaya matahari. Faktor-faktor lingkungan tersebut berpengaruh terhadap penyebaran jenis-jenis tumbuhan dan pertumbuhannya.

\section{Vegetasi Pohon Sekitar Plot Pengamatan}

Vegetasi pohon pada petak pengamatan didominasi oleh jenis tegakan induk pada tiap tegakan. Namun demikian, terdapat beberapa jenis lain pada petak-petak pengamatan. Jenis pohon pada sekitar plot pengamatan dalam setiap tegakan pengamatan dapat dilihat pada lampiran 2.

Dari hasil penelitian menunjukkan bahwa pada keempat petak tegakan pengamatan terdapat jenis pohon lain selain tegakan utama yang menyusun komposisi tegakan, namun jumlahnya yang sangat sedikit. Jenis penyusun ini dapat terjadi dikarenakan areal arboretum Anggori yang berbatasan dengan hutan alam, benih dari tegakan petak lain yang terbawa oleh 
vektor dan tumbuh dalam tegakan ataupun karena aktivitas manusia dalam petak tegakan. Tabel 1 menunjukkan juga bahwa jenis pohon pada sekitar plot pengamatan terbanyak pada petak pengamatan tegakan Manilkara fasciculate yaitu 17 jenis sedangkan pada petak tegakan Tectona grandis hanya berjumlah 7 jenis. Daun, ranting maupun bagian pohon tersebut yang gugur menjadi serasah dalam tegakan. Gugur serasah berperanan dalam memberikan input nutrien dalam tanah, yaitu sebagai penyumbang unsur hara dan sangat penting untuk menjaga keseimbangan ekosistem

\section{Biomassa dan Karbon Stock Tumbuhan Bawah}

Biomassa dinyatakan dalam ukuran berat kering per satuan luas. Jumlah berat kering tumbuhan bawah memiliki jumlah yang berbeda antar plot pengamtan dalam petak tegakan yang sama maupun antar petak tegakan pengamatan. Berat kering tumbuhan bawah setiap plot dalam petak tegakkan dapat dilihat pada tabel 1.

Tabel 1. Berat kering tumbuhan bawah pada hutan Anggori Manokwari

\begin{tabular}{|c|c|c|c|}
\hline Tegakan & Plot & $\begin{array}{c}\text { Berat Kering }(\mathrm{g} / \mathrm{m} 2) \\
\text { Tumbuhan Bawah }\end{array}$ & Karbon ton/Ha \\
\hline \multirow{4}{*}{ Manilkara fasiculate } & $1 \mathrm{~A}$ & 160 & 0,8 \\
\hline & 1B & 133 & 0,665 \\
\hline & $1 \mathrm{C}$ & 191 & 0,955 \\
\hline & Rata-rata & 161,333 & 0,807 \\
\hline \multirow{4}{*}{ Pometia coreacea } & $2 \mathrm{~A}$ & 136 & 0,68 \\
\hline & $2 \mathrm{~B}$ & 208 & 1,04 \\
\hline & $2 \mathrm{C}$ & 118 & 0,59 \\
\hline & Rata-rata & 154 & 0,77 \\
\hline \multirow{4}{*}{ Intsia bijuga } & $3 \mathrm{~A}$ & 164 & 0,82 \\
\hline & $3 \mathrm{~B}$ & 179 & 0,895 \\
\hline & $3 \mathrm{C}$ & 125 & 0,625 \\
\hline & Rata-rata & 156,000 & 0,78 \\
\hline \multirow{4}{*}{ Tectona grandis } & $4 \mathrm{~A}$ & 260 & 1,3 \\
\hline & $4 B$ & 100 & 0,5 \\
\hline & $4 \mathrm{C}$ & 89 & 0,445 \\
\hline & Rata-rata & 149,667 & 0,748 \\
\hline
\end{tabular}

Tabel 1 menunjukan bahwa rata-rata biomassa dan karbon stock tumbuhan bawah tertinggi diperoleh pada petak tegakan Manilkara fasciculate yaitu sebesar 161,333 sedangkan karbon stocknya 0,807 ton $\mathrm{C} / \mathrm{Ha}$. Rata-rata jumlah biomassa terendah diperoleh dari tegakan Tectona grandis yaitu 149,667 $\mathrm{gr} / \mathrm{m}^{2}$ sedangkan karbon stocknya yaitu 0,748 tonC/Ha. Komposisi vegetasi tumbuhan bawah pada plot-plot pengamatan di tegakan
Manilkara fasciculate memiliki jumlah individu dan jenis vegetasi penyusun lebih banyak dibandingkan dengan jumlah individu pada tegakan pengamatan lainnya. Hal inilah yang merupakan salah satu penyebab jumlah biomassa ataupun karbon stock pada tegakan Manilkara fasciculate lebih tinggi dibandingkan tegakan lainnya. Pada tumbuhan bawah, jumlah biomassa dan kandungan karbonnya dipengaruhi oleh komposisi vegetasi 
tumbuhan bawah penyusunnya (Windusari et al. 2012). Tanah yang subur dan ketersediaan airnya cukup akan membuat tumbuhan bawah dapat hidup dengan subur sehingga jumlahnya menjadi banyak. Kesuburan tanah dan ketersediaan air ini pun berkaitan pula dengan kondisi iklim, di musim penghujan ketersediaan air sangat mencukupi kebutuhan tanah dalam menyuplai air untuk tumbuhan yang hidup di atasnya sehingga tumbuhan pun dapat hidup dengan subur (Ariani dkk. 2014; Cabuy 2015).

\section{Karbon Stock Serasah}

Jumlah simpanan karbon pada suatu areal juga disumbangkan oleh jumlah karbon tersimpan dari serasah yang ada pada areal tersebut. Jumlah berat kering dan karbon tersimpan serasah dapat dilihat pada Tabel 2 .

Tabel 2. Berat kering serasah tegakan hutan Anggori

\begin{tabular}{cccc}
\hline \multirow{2}{*}{ Tegakan } & Plot & Berat Kering $\left(\mathrm{g} / \mathrm{m}^{2}\right)$ & Karbon ton $/ \mathrm{Ha}$ \\
\hline \multirow{3}{*}{ Manilkara fasiculate } & Serasah & 0,475 \\
& 1A & 95 & 1,545 \\
& 1C & 309 & 1,575 \\
Pometia coreacea & Rata-rata & 315 & 1,20 \\
& 2A & 239,667 & 1,72 \\
& 2B & 344 & 2,04 \\
Intsia bijuga & 2C & 408 & 1,11 \\
& Rata-rata & 222 & 1,62 \\
& 3A & 324,667 & 1,565 \\
Tectona grandis & 3B & 313 & 1,125 \\
& 3C & 225 & 1,315 \\
& Rata-rata & 263 & 1,335 \\
& 4A & 267,000 & 0,48 \\
& 4B & 96 & 1,14 \\
& 4C & 228 & 1,235 \\
\hline
\end{tabular}

Tabel 3 menunjukkan bahwa berat kering maupun karbon stock serasah paling banyak terdapat pada petak Pometia coreacea yaitu $324,667 \mathrm{gram} / \mathrm{m}^{2}$ dan karbon stocknya 1,62 ton $\mathrm{C} / \mathrm{Ha}$ dibandingkan dengan tegakan pengamatan lainnya. Hal ini dikarenakan tutupan tajuk pada petak ini padat sehingga menyumbang serasah yang banyak. Jumlah biomassa dan karbon stock yang berasal dari serasah tergantung pada keragaman dan kerapatan tumbuhan serta kecepatan dan kemampuan gugurnya daun maupun ranting pohon dan vegetasi lain yang ada pada areal pengamatan. Jenis penyusun, tingkat kerapatan pohon, dan luas bidang dasar suatu tegakan akan berpengaruh terhadap produktivitas serasah suatu tegakan (Dephut, 1997 dalam Kurniasari, 2009). Suhu dan kelembaban udara mempengaruhi jatuhan serasah tumbuhan. Naiknya suhu udara akan menyebabkan menurunnya kelembaban udara sehingga transpirasi akan meningkat, dan untuk menguranginya maka daun harus segera digugurkan (Salisbury dan Ross, 1995). Perbandingan berat kering dan karbon stok tumbuhan bawah dan serasah pada setiap petak pengamatan dapat dilihat pada tabel 3 . 
Tabel 3. Berat kering serta karbon tumbuhan bawah dan serasah pada tegakan hutan Anggori

\begin{tabular}{lcccc}
\hline \multirow{2}{*}{ Tegakan } & \multicolumn{2}{c}{ Tumbuhan bawah } & \multicolumn{2}{c}{ Serasah } \\
\cline { 2 - 5 } & $\begin{array}{c}\text { Berat kering } \\
\left(\mathrm{gr} / \mathrm{m}^{2}\right)\end{array}$ & $\begin{array}{c}\text { Berat karbon } \\
(\text { tonC/Ha })\end{array}$ & Berat kering $\left(\mathrm{gr} / \mathrm{m}^{2}\right)$ & Berat karbon (tonC/Ha) \\
\hline Manilkara & 162 & 0,81 & 239,67 & 1,2 \\
fasiculate & 154 & 0,77 & 324,67 & 1,6 \\
Pometia coreacea & 156 & 0,78 & 267,1 & 1,32 \\
Intsia bijuga & 145,67 & 0,748 & 150,33 & 0,95 \\
Tectona grandis & & & \\
\hline
\end{tabular}

Nilai ini juga jauh lebih tinggi dibandingkan dengan karbon stock pada tanaman bawah di tegakan Araucaria klinkii di hutan Pendidikan Anggori yaitu 14,85 gr $\mathrm{C} / \mathrm{m}^{2}-18,65 \mathrm{grC} / \mathrm{m}^{2}$ (Kutiman, 2018), namun lebih rendah dari karbon stok di kawasan suksesi alami pada area pengendapan Tailing PT. Freeport Indonesia yaitu mencapai 27,35 ton/Ha untuk tumbuhan bawah dan 3,14 ton/Ha untuk serasah pada blok B4BB di area tersebut (Windusari et al. 2012). Perbedaan nilai karbon ini dapat dikarenakan perbedaan vegetasi yang tumbuh dan juga kondisi lingkungan yaitu tapak maupun iklim pada area pengamatan. Hutan alami merupakan penyimpan karbon $\mathrm{C}$ tertinggi bila dibandingkan dengan sistem penggunaan lahan (SPL) pertanian, dikarenakan keragaman pohonnya yang tinggi, dengan tumbuhan bawah dan serasah di permukaan tanah yang banyak (Hairiah dan Rahayu, 2007).

\section{DAFTAR PUSTAKA}

Andini AR. 2017. Komitmen Jepang terhadap penanganan ilegal logging di Indonesia dalam kerangka Asia Forest Partnership Tahun $2002-2012$.

Ariani, Arief S, Abdul W. 2014. Biomassa dan karbon tumbuhan bawah sekitar danau Tambing pada kawasan Taman Nasional Lore Lindu. Warta Rimba, 2 (1): 164-170.

Cabuy RL. 2015. Age, diameter, height, crown, trunk, and biomass contained relationships of semi-arid Senegalese tree species. Mini
Project. Forestry Department, Michigan State University. 10.13140/RG.2.2.13324.92804.

Griffiths T. 2007. Pencegahan deforestasi dan hak-hak masyarakat adat dan komunitas lokal; terjemahan Ima Susilowati. Forest People Programme.

Hairiah K, Rahayu S. 2007. Pengukuran "karbon tersimpan" di berbagai macam penggunaan lahan. World Agroforestry Centre. Bogor.

Kartasapoetra G. 1992. Budidaya tanaman berkhasiat obat: kunyit (kunir). PT. Rineka Cipta. Jakarta

Kementrian LHK. 2016. Luas kawasan hutan dan kawasan konservasi perairan Indonesia 2016. http://www.menlhk.go.id/berita-129dataset-lingkungan-hidup-dankehutanan.html.

Krisnawati H, Imanuddin R, Adinugroho WC, Hutabarat S. 2015. Standard methods for estimating greenhouse gas emissions from forests and peatlands in Indonesia. Version 2, Research, Development and Innovation Agency, Ministry of Environment and Forestry.

Kurniasari S. 2009. Produktivitas serasah dan laju dekomposisi di kebun campur Senjoyo Semarang Jawa Tengah serta uji laboratorium anakan Mahoni (Swietenia macrophylla King) pada beragam dosis kompos yang dicampur EM4. Tesis Sekolah 
Pascasarjana Institut Pertanian Bogor. Bogor.

Kutiman IS. 2018. Inventarisasi karbon pada tegakan Araucaria klinkii di hutan Pendidikan Anggori Unipa. Karya Ilmiah Budidaya Hutan Fakultas Kehutanan UNIPA. Manokwari.

Mamusung EY. 2005. Analisis pendapatan pada industri mebel rotan di Kota Sorong. Skripsi Jurusan Kehutanan Fakultas Kehutanan UNIPA. Manokwari.

Salisbury FB, Ross CW. 1995. Fisiologi tumbuhan-Jilid 3; Perkembangan tumbuhan dan fisiologi lingkungan; terjemahan Diah R Lukman dan Sumaryono. ITB Bandung. Bandung.

Suryani. 2013. Proyeksi emisi gas rumah kaca 2012-2030. Prosiding Seminar dan Peluncuran Buku Outlook Energi Indonesia. Windusari Y, Nur APS, Yustian N, Zulkifli H. 2012. Dugaan cadangan karbon biomassa tumbuhan bawah dan serasah di kawasan suksesi alami pada area pengendapan tailing PT. Freeport indonesia. Biospecies, 5 (1): 22-28. 


\section{LAMPIRAN}

Tabel 1. Jumlah jenis dan individu tumbuhan bawah

\begin{tabular}{|c|c|c|c|c|}
\hline \\
\hline Tegakan & Plot & No & Jenis Tumbuhan Bawah & $\begin{array}{c}\text { Jumlah } \\
\text { Individu }\end{array}$ \\
\hline \multirow{16}{*}{$\begin{array}{l}\text { Manilkara } \\
\text { fasiculate }\end{array}$} & \multirow{4}{*}{$1 \mathrm{~A}$} & 1 & Donax cannaeformis & 6 \\
\hline & & 2 & Ficus sp & 2 \\
\hline & & 3 & Photos rumphii & 2 \\
\hline & & 4 & Selaginella willdenowii & 1 \\
\hline & \multicolumn{4}{|c|}{ Total individu $=11$} \\
\hline & \multirow{6}{*}{$1 \mathrm{~B}$} & 1 & Antiaris toxicaria & 1 \\
\hline & & 2 & Flagelaria indica & 2 \\
\hline & & 3 & Lansium domesticum & 2 \\
\hline & & 4 & Massia glauca & 1 \\
\hline & & 5 & Philodendron $\mathrm{sp}$ & 2 \\
\hline & & 6 & Selaginella willdenowii & 4 \\
\hline & \multicolumn{4}{|c|}{ Total individu $=12$} \\
\hline & \multirow{4}{*}{$1 \mathrm{C}$} & 1 & Aglaia spectabilis & 1 \\
\hline & & 2 & Carallia brachiata & 1 \\
\hline & & 3 & Chionanthus macrocarpa & 1 \\
\hline & & 4 & Diplasium esculente & 2 \\
\hline \multirow[t]{8}{*}{ Tegakan } & \multirow[t]{8}{*}{ Plot } & No & Jenis Tumbuhan Bawah & $\begin{array}{l}\text { Jumlah } \\
\text { Individu }\end{array}$ \\
\hline & & 5 & Donax cannaeformis & 2 \\
\hline & & 6 & Entandrophragma sp & 2 \\
\hline & & 7 & Ficus $\mathrm{sp}$ & 2 \\
\hline & & 8 & Lansium domesticum & 1 \\
\hline & & 9 & Philodendron $\mathrm{sp}$ & 2 \\
\hline & & 10 & Pimelodendron amboinicum & 1 \\
\hline & & 11 & Selaginella wildenowii & 11 \\
\hline & & & Total ind & $\mathrm{u}=26$ \\
\hline \multirow{9}{*}{$\begin{array}{l}\text { Pometia } \\
\text { coreacea }\end{array}$} & \multirow{5}{*}{$2 \mathrm{~A}$} & 1 & Diplasium esculente & 4 \\
\hline & & 2 & Ficus sp & 8 \\
\hline & & 3 & Neprolepis biserrata & 3 \\
\hline & & 4 & Philodendron sp & 1 \\
\hline & & 5 & Pollia tyrsiflora & 1 \\
\hline & \multicolumn{4}{|c|}{ Total individu $=17$} \\
\hline & \multirow{3}{*}{$2 \mathrm{~B}$} & 1 & Entandrophragma $\mathrm{sp}$ & 2 \\
\hline & & 2 & Ficus $\mathrm{sp}$ & 10 \\
\hline & & 3 & Justisia gendarusa & 1 \\
\hline
\end{tabular}




\begin{tabular}{|c|c|c|c|c|}
\hline & & 4 & Pometia coreacea & 1 \\
\hline & & 5 & Centhotheca sp & 3 \\
\hline & \multicolumn{4}{|c|}{ Total individu $=17$} \\
\hline & \multirow{5}{*}{$2 \mathrm{C}$} & 1 & Gonsenia & 1 \\
\hline & & 2 & Lansium domesticum & 4 \\
\hline & & 3 & Photos rhumpii & 1 \\
\hline & & 4 & Philodendron $\mathrm{sp}$ & 1 \\
\hline & & 5 & Selagenella wildenowii & 7 \\
\hline & \multirow{6}{*}{$3 \mathrm{~A}$} & \multicolumn{3}{|c|}{ Total individu $=14$} \\
\hline \multirow{17}{*}{ Intsia bijuga } & & 1 & Aglaia spectabilis & 1 \\
\hline & & 2 & Anamirta cocculus & 1 \\
\hline & & 3 & Ficus Sp. & 12 \\
\hline & & 4 & Mallotus Sp. & 1 \\
\hline & & 5 & Piper aduncum & 2 \\
\hline & \multicolumn{4}{|c|}{ Total individu $=17$} \\
\hline & \multirow{4}{*}{$3 \mathrm{~B}$} & 1 & Ficus Sp. & 10 \\
\hline & & 2 & Neprolepis biserrata & 3 \\
\hline & & 3 & Sauropus androgynus & 1 \\
\hline & & 4 & Vitis Sp. & 1 \\
\hline & \multicolumn{4}{|c|}{ Total individu $=15$} \\
\hline & \multirow{6}{*}{$3 \mathrm{C}$} & 1 & Anamirtha cocollus & 1 \\
\hline & & 2 & Ficus Sp. & 8 \\
\hline & & 3 & Intsia bijuga & 1 \\
\hline & & 4 & Neprolepis biserrata & 2 \\
\hline & & 5 & Piper aduncum & 1 \\
\hline & & 6 & Pollia $\mathrm{sp}$ & 1 \\
\hline & \multicolumn{4}{|c|}{ Total individu $=14$} \\
\hline Tegakan & Plot & No & Jenis Tumbuhan Bawah & $\begin{array}{l}\text { Jumlah } \\
\text { Individu }\end{array}$ \\
\hline \multirow{12}{*}{$\begin{array}{l}\text { Tectona } \\
\text { grandis }\end{array}$} & \multirow{3}{*}{$4 \mathrm{~A}$} & 1 & Diplasium esculente & 3 \\
\hline & & 2 & Lansium domesticum & 2 \\
\hline & & 3 & Selaginella wildenowii & 13 \\
\hline & \multicolumn{4}{|c|}{ Total individu $=18$} \\
\hline & \multirow{6}{*}{ 4B } & 1 & Amomum acculeactum & 1 \\
\hline & & 2 & Diplasium esculente & 2 \\
\hline & & 3 & Ficus Sp. & 3 \\
\hline & & 4 & Philodendron $\mathrm{sp}$ & 1 \\
\hline & & 5 & Pometia coreacea & 1 \\
\hline & & 6 & Selaginella wildenowii & 10 \\
\hline & \multicolumn{4}{|c|}{ Total individu $=18$} \\
\hline & $4 \mathrm{C}$ & 1 & Anamirta cocculus & 1 \\
\hline
\end{tabular}




\begin{tabular}{|l|l|l|l|c|}
\hline \multirow{4}{*}{} & 2 & Costus spesiosus & 2 \\
\cline { 2 - 4 } & 3 & Diplasium esculente & 1 \\
\cline { 2 - 4 } & 4 & Ficus Sp. & 2 \\
\cline { 3 - 4 } & 5 & Miremia peltata & 1 \\
\hline & 6 & Pollia thyrsiflora & 8 \\
\hline & 7 & Selaginella wildenowii & \multicolumn{2}{|c|}{ Total individu $=16$} \\
\hline
\end{tabular}

Tabel 2. Vegetasi pohon di sekitar plot pengamatan

\begin{tabular}{|c|c|c|}
\hline Petak & Plot & Jenis Vegetasi Tingkat Pohon \\
\hline \multirow{21}{*}{ Manilkara fasciculate } & \multirow{7}{*}{$1 \mathrm{~A}$} & Adina multivolia \\
\hline & & Litsea ladermanii \\
\hline & & Spathodea campanulata \\
\hline & & Octomeles sumatrana \\
\hline & & Artocarpus altilis \\
\hline & & Euodia elleryana \\
\hline & & Manilkara fasciculate \\
\hline & \multirow{7}{*}{$1 \mathrm{~B}$} & Pometia coreacea \\
\hline & & Medusanthera laxiflora \\
\hline & & Pisonia umbellifera \\
\hline & & Cananga odorata \\
\hline & & Lansium domesticum \\
\hline & & Premna corymbosa \\
\hline & & Spathodea campanulata \\
\hline & \multirow{7}{*}{$1 \mathrm{C}$} & Entandrophragma sp \\
\hline & & Horsfieldia irya \\
\hline & & Pometia coreacea \\
\hline & & Artocarpus fresianus \\
\hline & & Aglaia spechtabilis \\
\hline & & Pometia pinnata \\
\hline & & Pometia coreacea \\
\hline \multirow{5}{*}{ Pometia coreacea } & \multirow{5}{*}{$2 \mathrm{~A}$} & Antiaris toxicaria \\
\hline & & Osmoxyllon globulare \\
\hline & & Premna corymbosa \\
\hline & & Dracotomelon dao \\
\hline & & Streblus elongata \\
\hline
\end{tabular}


Lanjutan Tabel 2.

\begin{tabular}{|c|c|c|}
\hline Petak & Plot & Jenis Vegetasi Tingkat Pohon \\
\hline & \multirow{5}{*}{$2 \mathrm{~B}$} & Pimelodendron amboinicum \\
\hline & & Myristica fatua \\
\hline & & Medusanthera laxiflora \\
\hline & & Horsfieldia parviflora \\
\hline & & Cinamomun cullilawang \\
\hline & \multirow{6}{*}{$2 \mathrm{C}$} & Instia bijuga \\
\hline & & Artocarpus altilis \\
\hline & & Artocarpus altilis \\
\hline & & Pimelodendron amboinicum \\
\hline & & Calicarpa longifolia \\
\hline & & Alstonia scholaris \\
\hline \multirow{13}{*}{ Intsia bijuga } & \multirow{5}{*}{$3 \mathrm{~A}$} & Dracontomelon dao \\
\hline & & Calicarpa longifolia \\
\hline & & Octomeles sumatrana \\
\hline & & Peterocarpus indicus \\
\hline & & Premna corymbosa \\
\hline & \multirow{4}{*}{$3 \mathrm{~B}$} & Vitex pinnata \\
\hline & & Aglaia odorata \\
\hline & & Artocarpus altilis \\
\hline & & Euodia elleryana \\
\hline & \multirow{4}{*}{$3 \mathrm{C}$} & Artocarpus altilis \\
\hline & & Valcataria mollucana \\
\hline & & Valcataria mollucana \\
\hline & & Dracontomelon dao \\
\hline \multirow{9}{*}{ Tectona grandis } & \multirow{4}{*}{$4 \mathrm{~A}$} & Mallotus rhizinoides \\
\hline & & Pometia Pinatta \\
\hline & & Ficus nodosa \\
\hline & & Ficus variegata \\
\hline & \multirow{4}{*}{$4 \mathrm{~B}$} & Ficus chrysolepis \\
\hline & & Endospermum moluccanum \\
\hline & & Pometia coreacea \\
\hline & & Ficus tracypison \\
\hline & $4 \mathrm{C}$ & Ficus nodosa \\
\hline
\end{tabular}




\begin{tabular}{|l|l|}
\hline \multirow{2}{*}{} & Endospermum moluccanum \\
\hline \multirow{2}{*}{} & Endospermum moluccanum \\
\hline & Pometia coroace \\
\hline
\end{tabular}

